This is an author-produced PDF of an article published in Teaching in Higher Education, copyright Taylor \& Frances. The definitive publisher-authenticated version is available online:

Harrison, S. \& Grant, C. (2015). Exploring of new models of research pedagogy: Time to let go of master-apprentice style supervision? Teaching in Higher Education 20:5, 556-566. DOI: $10.1080 / 13562517.2015 .1036732$

\title{
Exploring of new models of research pedagogy: Time to let go of master-apprentice style supervision?
}

\author{
Scott Harrison and Catherine Grant
}

\author{
Queensland Conservatorium, Griffith University, Brisbane, Australia
}

\begin{abstract}
While the traditional one-to-one supervisory model of higher research degree training clearly has its advantages, some research suggests that the model also has significant drawbacks, including its typically - but not inherently - hierarchical nature. Nevertheless, this pedagogical model remains the default for higher research pedagogy across most institutional contexts. Using the discipline of music as a case study, where growing interest in practice-based research has lately demanded considerable fluidity in supervisory practices, this research explores the benefits, challenges and disadvantages of one-to-one models of supervision. Drawing on semi-structured interviews, dialogue forums, survey data, the extant literature, and observations of practices at selected higher music education institutions in Australia, the UK, Belgium, and the Netherlands, it recommends and suggests ways to implement more 'horizontal' approaches to research pedagogy. The authors hope that the findings and recommendations of this research may improve teaching and learning experiences and outcomes in higher research degrees in music and the creative arts, and stimulate a reflection of supervisory approaches more generally across the sector.
\end{abstract}

Keywords: collaborative learning, communities of practice, higher degree research, higher research education, supervision.

\section{Learning and teaching in higher research degrees: Contexts and conventions}

The conventional one-to-one supervisor-student model of Higher Degree Research (HDR) training remains a stalwart of higher education, and much of the literature endorses the belief that quality supervisor support through higher degree research studies is key to students' success (e.g. Gurr, 2001; Pearson and Brew, 2002; Sinclair, 2004). Some studies point to such supervision as a factor in students' timely completion of higher research degrees and more satisfactory employment upon completion (Wisker, 2005; Platow, 2012). But higher degrees are by no means immune to the shifts in tertiary education currently taking place in much of the Western world. At the international level, technological developments are one example of such a shift, demanding and driving global innovations in learning and teaching, including blended and online formats. At the national level, financial pressure on the higher education sector is another. Funding cuts have in turn generated departmental and institutional challenges that directly affect staff, such reduced teaching resources and/or support mechanisms, increased workload, and the continual necessity to justify expenditure. Students are affected by each of these circumstances.

Moreover, a rise in the diversity of degrees - including research degrees, as indicated by the growth 
of professional doctorates - in turn has contributed to a more diverse student population, with a wider range of learning styles and needs (Engebretson et al, 2008), and a wider range of motivations for undertaking study (Harrison, 2011). Given the increasing diversity of career pathways sought out by graduates (including HDR graduates) combined with the fact that only a minority find work in academia following their studies, robust employability as well as academic skills are increasingly essential (Cumming et al, 2009). For HDR students, the consequences of these shifts include the need to be able to deal with fast-changing educational models, heightened expectations of autonomy, and pressure to complete in shorter timeframes.

In this at-times challenging educational environment, the traditional one-to-one model of supervision has fallen under scrutiny. Some studies have cast doubt that this model is able to meet the demands created by increasing HDR student diversity, institutional accountability, and the wider range of post-HDR career pathways (e.g. Yeatman, 1995). Shacham and Od-Cohen (2009) argue that traditional models of research education fail to sufficiently prepare students for a fast-changing workplace environment where collaboration is increasingly the norm. Engebretson et al (2008) question the usefulness of these models in cases where the student has extensive industry experience (as is standard for those enrolled in professional doctorates), and Brien and Williamson connect the challenges of supervision to the wider issues relating to the changing role and nature of the higher education sector at large:

[T]he supervisor-student relationship today faces many pressures: workload demands; internal and external competition; conflicting individual needs; new modes of communication; an increasingly client-focused, customer-normed higher education sector; and a growing emphasis on metric evaluative mechanisms for measuring research quality, which includes the number of research degree completions. (2009)

Despite some recognised limitations of the traditional supervisory model of research higher education (or 'research training', the term with currency in the Australian context), until relatively recently many academic studies adopted the approach of attempting to improve the mechanisms of that very model, rather than investigating alternatives. Yeatman (1995), for example, acknowledges some shortcomings of the one-to-one approach, and describes how a supervision log may be used to record and clarify advice given in supervisory meetings, thereby improving it. Another example is Murphy (2009), who in making suggestions for improving the model, notes that the mismatch between students' and supervisors' preferences regarding the content of supervision contributes to poor student experience of HDR study and longer than average completion times. The usefulness of one-to-one supervision notwithstanding (described further below), the changes in the higher education environment combined with the limitations of classic one-to-one supervision call for new ways of conceptualising HDR training. This is increasingly reflected in the literature on higher research pedagogy, which more recently has tended to explore alternatives to the traditional oneto-one approach (e.g. Boud and Lee, 2005; Engebretson et al, 2008; Lee, 2012; Westerlund and Karlsen, 2013).

\section{Concepts and practices of one-to-one}

One-to-one pedagogy is not necessarily hierarchical - for example, it may be Socratic, dialogic, or bidirectional. It is therefore important to distinguish it from the more specific approach to one-to-one known as 'master-apprentice', which is founded upon the transmission of knowledge and/or skills 
from a highly knowledgeable and/or highly skilled individual to one less so, who then (typically passively) receives and assimilates that knowledge. Even when one-to-one interactions are not explicitly hierarchical in nature - for example, where a research student is encouraged to learn by observing and emulating his or her supervisor in a laboratory (see Dysthe, 2002) - this kind of learning can still embody a master-apprentice-style transfer of information to the student, who may have little control over the content, pace, and direction of learning.

Various definitions of supervision exist in the pedagogical literature, encompassing a range of perspectives on supervisor authority, student autonomy, and the nature of supervisor-student relationships and interactions (e.g. Cargill, 2000; Dysthe et al, 2006; Lee, 2008; Samara, 2006). As it is traditionally conceived and practiced in higher education institutions in much of the Western world, one-to-one HDR pedagogy arguably still tends towards an inherently hierarchical model, as is perhaps indicated by the very use of the term supervision to describe it ('the action or function of overseeing, directing, or taking charge of a person, organization, activity, etc.'; OED, 2013).

Even if current models of higher degree research supervision are commonly hierarchical, though, it would be wrong to assume that overt authority or establishment of a hierarchy is unambiguously negative. In exploring preferred supervisory practices of engineering supervisors versus candidates, Murphy (2009) found that although the majority of supervisors focused on the professional and personal growth of the candidate and saw their role as guiding rather than controlling the research, the majority of students in the study preferred prescriptive, task-oriented, controlling supervision. For some HDR students, at least at certain stages of their candidature, a more prescriptive approach to supervision may work well (a consideration raised again later in this paper).

\section{Alternative models for research pedagogy}

Since at least the 1990s, researchers have explored alternative models for research pedagogy that disrupt the characteristically hierarchical nature of supervisory practices. Burnett (1999), for example, examined HDR supervision through a 'collaborative cohort model' (CCM), contrasting it with a 'master-apprentice' approach. CCM involved students attending a 'dissertations meeting' to discuss their own and other students' research, facilitated by a mentor academic. Burnett found that students who attended these meetings felt less isolated, were more likely to complete their studies, and developed a wider range of skills than those who did not. More recently, drawing on ideas of transference from psychoanalytics, Hecq (2009) has described interactive narrative pedagogy as a way of displacing overtly authoritative relationships between supervisor and student. She suggests that this approach encourages engagement between student and supervisor and enhances both students' and supervisors' knowledge (including self-knowledge). Another creative and highly innovative approach to HDR supervision is outlined by Carter (2010), who describes the use of psychodrama as method of externalising thoughts and ideas within the supervision session. Objects are chosen to 'be' particular ideas or groups of people involved in the research and each is placed spatially (and moved, as appropriate) to represent the relationship it has to the others. Ideas, thoughts, memories and experiences become embodied through their kinaesthetic enactment. The relationship between the supervisor and student moves away from one of hierarchical dependency as the student develops an internal sense of authority. Various other examples of 'alternative paradigms' for HDR supervision exist (e.g. Biggs and Büchler, 2009; Westerlund and Karlsen, 2013). 
Team supervision (Dysthe 2002, Samara 2006) is one way to dissipate verticality in research training, but it is not the only way. Harrison and Dwyer (under review) propose a model founded on Gee's belief that 'people learn best when their learning is part of a highly motivated engagement with social practices that they value' (2004, p. 70). They advocate for establishing, within the HDR context, 'affinity spaces' (Gee, 2004) - learning environments characterised by a common space and a common endeavour shared by masters and newcomers, where leadership is 'porous', where forms and routes to participation are many, and where intensive, extensive, individual, distributed, dispersed, and tacit forms of knowledge are all encouraged and honoured. They suggest that affinity spaces could be fostered through dialogue forums, a collaborative activity in which participants explore issues and relationships on an equitable basis, facilitating reciprocal learning and knowledge production (see Bohm et al, 1991). In the public policy arena, it has been found that dialogue forums 'promote many different types of learning' and 'challenge and change participants' attitudes and opinions as ideas are discussed and negotiated' (Davies et al, 2008). The literature on dialogue forums indicates that there can be barriers to dialogue taking place; within the HDR context, careful consideration might be given to the structure of the forum, the skills and institutional positioning of the facilitator, and ways to promote an environment whereby participants interact and create meaning from the dialogue.

\section{Practice-based HDRs in the creative arts}

While many challenges to the higher education sector are sector-wide, some are compounded when dealing with academic disciplines that are relatively new. In the time-honoured science disciplines, studies have indicate that discrepancies still arise between preferences of students and supervisors on the role and nature of supervision (e.g. Murphy, 2009); this is despite the frequent informal interactions in the lab or in team meetings that often influence the way the student-supervisor relationship is built and maintained in those disciplines (Oxford Learning Institute, 2012). Such opportunities for regular informal interactions are less common in the humanities and social sciences (OLI, 2012). Particularly in creative arts disciplines like music, the potential for mismatches between supervisor-student expectations and approaches may be magnified, and 'unclear or differing expectations of supervisor-student roles and relationships' may exacerbate existing challenges in these 'non-traditional' discipline areas (Brien and Williamson, 2009, p. 1).

In the creative arts, a desire to better understand the nexus between creative practice and research - a field of study variously and contentiously termed practice-led, practice-based, or practice-as research - has recently also stimulated growing scholarly interest in the topic of what might constitute appropriate approaches to supervising such research. In themselves, the analogies between learning creative arts practices and 'learning to research' have potential to stimulate new ways of thinking about strategies and systems for research pedagogy. Gaunt (2011) notes in passing the parallel between one-to-one instrumental tuition and supervisory research models; Harrison (in press) refers to similarities and dissimilarities between teaching singing in the studio and teaching research students; and Bresler (2009) observes likenesses between research education and musicianship, both of which require the student to learn to perceive, listen and improvise, and demand 'a strong intrinsic motivation in order to persist when the answer is not evident' (p. 7).

Analogies aside, in most conservatoires the master-apprentice model is thoroughly embedded in institutional psyche via the continued emphasis on that centuries-old style of learning a musical instrument. Conservatoires continue to 'display considerable respect for this model, promoting its 
existence as an "internationally recognized" standard of teaching, one that needs to be "safeguarded" for a country to remain musically competitive on the international scale' (Carey et al, 2013 , p. 357). Despite a number of studies over the last decade or more raising concerns with oneto-one instrumental and vocal teaching, including the hierarchical, de-contextualised, assessmentoriented approach often taken (e.g. Persson, 1994; Burwell, 2005; Presland, 2005; Carey \& Grant, in press), individual lessons in the master-apprentice manner are still typically perceived to be an 'indispensable, intense and intricate' part of instrumental and vocal learning (Gaunt, 2007, p. 230). Arguably, the philosophies and approaches found in one-to-one undergraduate music training are to some extent carried over to conservatoire postgraduate research supervision, particularly in those projects where the nature of practice is a central focus (that is, in practice-based research).

Promisingly, though, the unique characteristics of practice-based research found in creative arts disciplines like music open up a range of opportunities for exploring innovative and improved models for research supervision and training. Institutions and their staff are increasingly recognising that practice-based research, where creative practice is carried out or creative output is produced as an integral component, demands considerable fluidity in supervisory practices. Stock (2009), for example, describes the complexities and particularities of supervising HDR students in dance, a discipline where knowledge is primarily embodied and there is a close relationship between theory and practice. Evans and Gandolfo (2009) suggest that academia is structured in ways that are individualistic, competitive and hierarchical, discouraging rather than facilitating collaboration; with focus on exploring supervisory approaches in practice-based visual arts and creative writing research, those authors advocate a supervisory approach that positions the supervisor not as an expert or master, but alongside the student, sharing the ownership and responsibility for the research. Such models may align more easily with the processes and characteristics of practicebased research in the arts disciplines, where fostering creativity, vision and imagination in research students may be as crucial a part of research supervision and training as the development of more academic skills.

From these foundations, this paper examines and problematises the characteristically hierarchical nature of one-to-one supervision in research higher degrees in music. The study is situated within a wider Australian-led research project (2012-2013) that aimed to explore and enhance training practices and learning outcomes in music higher research degrees, and to identify innovative approaches, tools and strategies to support successful practices. This current paper draws on data gathered through an online survey on practice-based research training, completed by 72 supervisors and 73 students from across eleven countries in Europe, Asia, Australia, Africa, and the Americas over a six-month period to May 2013. To increase validity and reliability within the scope of the study, survey data are triangulated with two further sources: first, insights from forums and workshops on research education conducted during 2012 and 2013 at higher music institutions in the UK, Belgium and the Netherlands, along with observations of research pedagogy at those institutions; and second, a series of 'dialogue forums' and semi-structured interviews with supervisors and students at one Australian conservatoire. Five forums (two with HDR students and three with HDR supervisors) and ten interviews (five with students, five with supervisors) were facilitated over a period of eight months to February 2013. Forums and interviews were transcribed, analysed and interpreted, themes being generated inductively. Survey data were analysed and interpreted separately, then compared with those from the forums and interviews. Further information on approach and method are detailed in Harrison (2013). 


\section{Student and supervisor preferences in supervision}

The present study confirmed that preferences of supervisors and students about the content of research supervision indeed did not always align. In general, supervisors placed more importance than students on focusing on technical matters relating to research. The majority of supervisors who responded to the survey, for example, thought it 'very important' to advise their students on locating resources (33 of 47 , or $70 \%$ of supervisor respondents), developing writing skills (30 of 47 , or $64 \%$ ), and academic protocols and processes ( 28 of 47 , or $60 \%$ ). Thirty-five of 48 supervisors (73\%) felt that presenting at conferences were a 'very valuable' part of their students' research training, as opposed to only $53 \%$ of students. Students reported that they felt it was important for their supervisors to advise them on publishing, scholarships, symposia, and other matters that may have an impact on their 'overall progression and development', both during their studies and beyond. These data point to the diversity of skills that may (arguably should) be developed through the course of a research higher degree, as well as the difficulty in reaching a consensus on which of these skills should be the focus of research supervision. This is true both at a general level and at the level of each individual student: student needs will differ widely, both in terms of their current abilities and their future professional (and personal) aspirations.

Some supervisors did refer to the importance of providing 'professional and personal guidance and mentoring' to their students, but as Hockey and Allen-Collinson (2000) found in interviewing 50 supervisors of practice-based research students, balancing pastoral and intellectual support was a recurring theme, and proved a challenge for some. Several comments made in interviews and dialogue forums and through the survey indicated that supervisors were sometimes faced with decisions regarding the reasonable bounds of the supervisor-student relationship:

I am not a therapist and make a distinction so that should students have personal issues I recommend that they find an appropriate person to fulfil the therapeutic relationship. If students rely upon me for therapy it is not healthy for either of us. (Supervisor survey respondent \#60, May 16, 2013)

I've gotten to know most of the ones I've supervised quite well. ... What are the limits? Because getting to know them too well can be a downside too. Because you can't be really critical. (Supervisor dialogue forum participant \#3, 20 Sept, 2012)

Because of the autoethnographic nature of his study, we were getting into his personal life, but that was starting to become very, very complicated because he was learning a lot of things about himself that he had to confront and challenge. I'm not a psychologist, but he was coming to me with a number of psychological issues. I had to somehow negotiate those and put them into a scholarly context without really understanding them as a psychologist. . .. whenever he talked about those sorts of things I knew that it wasn't my place to start delving into all of that. (Student interview \#2, 10 April, 2013)

The impossibility of a single supervisor being able to fulfil all the needs of their students suggests the importance of facilitating students' access to a range of diverse resources during their studies. For research-related matters, one possible approach involves the distribution of supervision among a team (Dysthe 2002, Samara 2006). The various skills and strengths of each supervisor may then assist the student in complementary ways, and provide more complete support than would be possible from a single supervisor. Some of the institutions engaged in this study already had a team- 
supervision approach in place, most commonly with two supervisors but sometimes with three or more.

In this study, students expressed a range of views about team supervision. Some students felt this was a good idea, mostly for the diversity of perspectives, skills and experience that model affords:

The diversity and strengths of each supervisor can assist in and enrich various facets of the research as well as [the student] having access to the relevant contacts that each might have.

(Student survey respondent \#45, $30 \mathrm{Dec}, 2012$ )

One student with an interdisciplinary research topic felt that having two supervisors provides 'coverage'; 'it also means that the supervisors can discuss issues together - they can develop understanding of what I am doing [together]'. This student felt that having one supervisor could be 'catastrophic' (student survey respondent \#6, 9 September, 2012).

Other students liked the idea of a team of supervisors considerably less, primarily citing the concern that the team 'could become too dispersed' or 'cause confusion and misunderstandings since everyone may have different ideas' (a concern raised in Burnett, 1999, who found that conflict sometimes arose in 'dissertations meetings' when the supervisor and meeting facilitator offered the student differing advice). One student felt that exactly two supervisors 'work[ed] well' because of the different perspectives each brings, adding: 'I think more could be confusing; one, not enough' (student survey respondent \#68, 8 May, 2013). Another preferred only one supervisor:

I would prefer not to [have team supervision] as conflicting ideas may add difficulty to the process and may potentially prolong my progress. It may also be difficult to organise spontaneous meetings with more than one supervisor. (Student survey respondent \#34, 7 Dec, 2012).

Another student suggested that a single supervisor may be sufficient, but only if he/she is 'good':

If the supervisor is good, one is all I want because you can waste time following different pathways from different sources. If one supervisor wasn't good, then I'd prefer two to counterbalance things. (Student survey respondent \#16, 30 Sept, 2012).

Some students suggested that an even wider network of support would be beneficial:

I think 2 [supervisors] is adequate to be meeting on a regular basis, however I think it would be very useful at times to be able to give my work to/have meetings face-to-face with other academics at the institution and get their advice and opinions. (Student survey respondent \#38, 10 Dec, 2012).

Like students, supervisors had divided views on whether they preferred to work within a team of supervisors. Some supervisors felt this was (or would be) beneficial for both students and supervisors:

Yes, because it brings a suite of experience and skills to the student's experience. (Supervisor survey respondent \#34, 16 Dec, 2012).

Yes. I am fatally flawed, as are we all. Students (ultimately) benefit from a (the right) team working together. (Supervisor survey respondent \#27, 11 Dec, 2012). 
Yes, in fact if this way of working should be effective it should be based on peer-to peer learning between supervisors. (Supervisor survey respondent \#39, 18 Dec, 2012).

Other supervisors were ambivalent or against working in a team - both for reasons of independence as well as the considerations of potential "confusion" for the students. In the survey, when asked whether they would like to work in a team, supervisor responses included:

Perhaps. It would depend on whether we share a similar emphasis on creative and text-based approaches to research. (Supervisor survey respondent \#41, 19 Dec, 2012).

No. I like the idea that I can provide the necessary supervision the student needs, although I am not closed to joint supervision. (Supervisor survey respondent \#23, 7 Dec, 2012).

Sometimes I do work in a team. This is most effective when the personalities and research goals coincide or complement each other. It does not work when one person believes $s /$ he is superior to the others on the team and under the rubric of being a team ensures that things will go the way they want it to go through manipulations. A team that works is a dream and the way life should be. A team that does not work is pure hell particularly for the candidate. (Supervisor survey respondent \#46, $20 \mathrm{Dec}, 2012$ ).

It is worth noting that even in with a supervisory team, student-supervisor hierarchies can still pertain.

\section{Synthesis and next steps}

Data from this study resonate with the literature suggesting that a predominantly or exclusively hierarchical model of HDR supervision and training is neither ideal nor sufficient. Three reasons may be argued for this. One, indicated in the comments reported in the previous section, is the difficulty inherent in a single supervisor being required to meet all the needs of the HDR student, from research-related, to emotional and psychological, to the development of a broad-ranging set of graduate attributes. Through the survey responses, dialogue forums and interviews, the students in this study identified a range of extra-supervisory experiences and activities that had a positive effect on their learning, including presenting at conferences; participating in faculty-based colloquia and seminars, university-wide training sessions, and reading and writing groups; becoming actively involved in 'the practical side' of the research field beyond their studies; preparing articles for peer review; interacting and networking with colleagues and visiting professionals and researchers; utilising website-based institutional training resources; engaging in reflective practice and observation; reading other dissertations; and reading books on the research process. Activities mentioned by supervisors as having a positive effect on their students' learning included preparing journal articles for peer review; co-authoring or co-presenting research papers with supervisors; participating in faculty-based colloquia and seminars, public presentations, media interviews, performances, workshops, training in research and writing skills; and reading widely. Nearly a decade ago now, Boud and Lee (2005) called for 'more systematic attention to be paid to the breadth and diversity of learning activities and relationships in research education'. The findings of this present study lend weight to Boud and Lee's proposition that research pedagogy should move beyond the vertical supervisor-student dyad to a more horizontal model, for example utilising communities of practice (Lave \& Wenger, 1991; Wenger, 1998), with the supervisor only one of many resources at the student' disposal. 
A second reason to break down the hierarchical master-apprentice model of research training is the need for a well-rounded skill set upon graduation. For the majority who find employment outside of academia, music HDR graduates are likely to face 'a lifetime of specialised work requiring multiple advanced skill sets in which they will continually learn and re-learn skills for performance in roles that may not have been invented yet' (Bridgstock and Hearn, 2012, p. 5). The eight dimensions of graduate capability identified by Cumming et al (2009) - inquiring, analysing, producing, communicating, teaching, managing, thinking and interacting - can be acquired through a number of means, structured (e.g. formal courses/training), semi-structured (peer-learning, dialogue, mentoring) or unstructured (student initiated internships, paid employment). What is distinctly unlikely is that all eight dimensions of capability may be solidly acquired through reliance on a single method of learning, with heavy reliance on one or two individuals, such as is the case in a hierarchical one-to-one model of research supervision. Worryingly, almost half the students who took the survey in this study ( 24 of 51 respondents, or $47 \%$ ) felt only 'a little prepared' or 'not prepared' for life beyond their degree, with responses indicating considerable anxiety about life post-graduation:

I am afraid my degree will not give me satisfying job opportunities and I am not satisfied with the job I have at the moment. (Student survey respondent \#64, 7 May, 2013)

Lack the networking skills and knowledge of how academic works, both of which are needed to make an academic career. (Student survey respondent \#51, 22 April, 2013)

I do feel disadvantaged by the fact that I will be over 30 by the time I finish my doctorate and will never have had a full-time job. I am also aware that it will be close to impossible for me to find a full-time job in Australia, let alone [my home city], so in that sense I feel quite unprepared. (Student survey respondent \#53, 11 Dec, 2012)

I think I know what needs to be done to pursue academic life but I also don't think I have any time or means to make those preparations, hence when the end comes I [am] going to be out in the cold. I fear it is going to be train wreck, actually. The 'little prepared' answer refers to the fact I know what needs to be done. But in practice, I can't get it done and write the thesis and survive the process. (Student survey respondent \#48, 7 Dec, 2012)

I am apprehensive about being seen as an 'expert' in my field, able to respond to frequent requests to provide answers, workshops, papers etc. (Student survey respondent \#47, 7 Dec, 2012)

This raises the question of the extent to which current models of research supervision and training sufficiently meet the needs of students (and industry). The fact that almost half the students in this study felt 'only a little prepared' or 'not prepared' for life post-graduation indicates considerable scope to improve HDR pedagogy for these students.

A third possible rationale for 'horizontalising' research education stems from those (hopefully) atypical instances where the supervisor-student relationship deteriorates, is dysfunctional, or simply doesn't 'gel'. This current study did not specifically gather data on the less positive experiences or aspects of supervision (for students or supervisors), and existing research on the extent of dysfunction in HDR supervisory relationships is minimal. However, anecdotal evidence (gathered through informal interactions with colleagues and students nationally and internationally during the wider project of which this study is a part) indicates that maintaining an optimal relationship 
throughout candidature can be a challenge for students and supervisors alike. This issue is not easy to investigate, not least because of the issue of power differentials that obtain. In their research, for example, Harrison and Dwyer (under review) met with difficulty in getting students to frankly share their less positive experiences of supervision, a challenge they suggest may be attributable to the themes of 'fear, power and hierarchy' that arose in at least one student's account of the supervisory relationship.

As an outcome of this study, a series of dialogue forums (Bohm et al, 1991) were trialled at the authors' institution, with the intent to create a non-hierarchical collaborative platform for students and supervisors to share experiences and ideas around supervision and research training, and ultimately to improve HDR learning and teaching experiences and practices. While the trial is still underway at the time of writing, preliminary feedback from supervisors and students indicate that the forums represent a potentially powerful platform for the exchange of ideas, tools, and experiences that may help break down the hierarchical structures of HDR learning and teaching, encourage peer teaching and learning, reduce reliance on the master-apprentice model (and on a single supervisor), increase the pool of resources available to students, help build relationships and support networks between and among students and supervisors, and reduce isolation in the HDR process for both students and supervisors. As such, the dialogue forums may prove to be one step towards 'horizontalising' the research pedagogy at this conservatoire. Further research will be needed to determine the success of this approach in terms of improving student and supervisor experience and improving graduate outcomes.

If, as Manathunga and Goozée (2007) contend, research education is based on a flawed assumption that research students have the skills to work autonomously and that academics know how to be effective supervisors by dint of having been through the process as students, the importance of exploring innovative pedagogical models and improving existing HDR training practice is clear. The relatively recent rise of practice-based research in creative arts disciplines opens up possibilities for imaginative explorations of new models of research pedagogy that steer away from exclusive or heavy reliance on the canonised, hierarchical, master-apprentice-style supervision. The potential benefits of doing so are many, including improved graduate outcomes, greater student preparedness for life post-degree, reduced isolation, and stronger support networks. These nonhierarchical models hold potential to improve research education well beyond the confines of the creative arts industries that have been the focus of discussion in this paper.

\section{Acknowledgements}

Thanks are due to all the HDR supervisors and students who participated in this study; to host institution Griffith University; to partner organisations International Society for Music Education, Cambridge University (UK), Sibelius Academy (Finland), and Orpheus Institute (Belgium); and to anonymous reviewers for their feedback. Support for the production of this article was provided by the Australian Government Office for Learning and Teaching, through a National Teaching Fellowship awarded to the first-named author. The views expressed in this article do not necessarily reflect the views of the Australian Government Office for Learning and Teaching. More information on the Fellowship project can be found at www.musicresearchspace.com.au. 


\section{References}

Biggs, M., \& Büchler, D. (2009). Supervision in an alternative paradigm. TEXT: The Journal of Writers and Writing Courses, 13(2). Retrieved 5 August, 2013, from http://www.textjournal.com.au/speciss/issue6/content.htm

Bohm, D., Factor, D. \& Garrett, P. (1991). Dialogue: A proposal. Retrieved 5 August, 2013, from http://www.david-bohm.net/dialogue/dialogue proposal.html

Boud, D. J., \& Lee, A. (2005). Peer learning as pedagogic discourse for research education. Studies in Higher Education, 30(5), 501-516.

Bresler, L. (2009). Research education shaped by musical sensibilities. British Journal of Music Education, 26(1), 7-25. doi: 10.1017/S0265051708008243

Bridgstock, R. \& Hearn, G. (2012). A conceptual model of capability learning for the 21st century Knowledge Economy. In D. Rooney, G. Hearn \& A. Ninan (Eds), Handbook on the Knowledge Economy, pp. 105-118. Cheltenham: Edward Elgar.

Brien, D. L. \& Williamson, R. (2009). Supervising the creative arts Research Higher Degree: Towards best practice. TEXT: The Journal of Writers and Writing Courses, 13(2). Retrieved 29 April, 2013, from http://www.textjournal.com.au/speciss/issue6/content.htm

Brien, D. L. (2009). Unplanned educational obsolescence: Is the 'traditional' PhD becoming obsolete? Journal of Media and Culture, 12(3). Retrieved 5 August, 2013, from http://journal.mediaculture.org.au/index.php/mcjournal/article/viewArticle/160

Burnett, P. C. (1999). The supervision of doctoral dissertations using a collaborative cohort model. Counselor Education and Supervision, 39, 46-52.

Burwell, K. (2005). A degree of independence: Teachers' approaches to instrumental tuition in a university college. British Journal of Music Education, 22(3), 199-215.

Carey, G., Bridgstock, R., McWilliam, E., \& Taylor, P. \& Grant, C. (2013). Characterising one-to-one conservatoire teaching: Some implications of a quantitative analysis. Music Education Research (online version). doi: 10.1080/14613808.2013.824954

Carey, G. \& Grant, C. (in press). Student and teacher perspectives on one-to-one pedagogy: Practices and possibilities. British Journal of Music Education. Manuscript accepted for publication 15 October 2013.

Cargill, M. (2000). Intercultural postgraduate supervision meetings: An exploratory discourse study. Prospect 15(2), 28-38.

Carter, P. D. (2010). Using action methods in post-graduate supervision. International Journal of Education \& the Arts, 11(1), 1-16.

Cumming, J., M. Kiley, M. Thomas, L. Hort, M. Pike, E. Evans \& A. Main (2009). Research graduate skills project [Final report. Retrieved 30 April, 2013, from http://www.gradskills.anu.edu.au

Davies, S., McCallie, E., Simonsson, E., Lehr, J.L., \& Duensing, S. (2008). Discussing dialogue: Perspectives on the value of science dialogue events that do not inform policy. Public Understanding of Science 18(3), pp. 338-353.

Deuchar, R. (2008). Facilitator, director or critical friend?: contradiction and congruence in doctoral supervision styles. Teaching in Higher Education, 13(4), 489-500. doi: $10.1080 / 13562510802193905$

Dysthe, O. (2002). Professors as mediators of academic text cultures. Written Communication, 19(4), 493-544. doi: 10.1177/074108802238010 
Dysthe, O., A. Samara, \& K. Westrheim. (2006). Multivoiced supervision of Master's students: A case study of alternative supervision practices in higher education. Studies in Higher Education 31(3), 299-318.

Engebretson, K., Smith, K., McLaughlin, D., Seibold, C., Terrett, G., \& Ryan, E. (2008). The changing reality of research education in Australia and implications for supervision: A review of the literature. Teaching in Higher Education, 13(1), 1-15. doi: 10.1080/13562510701792112

Evans, M. \& Gandolfo, E. (2009). Collaborating with the Enemy. TEXT: The Journal of Writers and Writing Courses, 13(2). Retrieved 5 August, 2013, from http://www.textjournal.com.au/speciss/issue6/content.htm

Gaunt, H. (2011). Understanding the one-to-one relationship in instrumental/vocal tuition in Higher Education: Comparing student and teacher perceptions. British Journal of Music Education, 28(2), 159-179.

Gee, J. 2004. Situated language and learning: A critique of traditional schooling. New York: Routledge.

Gurr, G.M. 2001. Negotiating the 'rackety bridge' - A dynamic model for aligning supervisory style with research student development. Higher Education Research \& Development 20, 81-92.

Hammond, J., K. Ryland, M. Tennant, \& D. Boud (2010). Building research supervision and training across Australian universities [Report]. Retrieved 30 April, 2013, from http://www.olt.gov.au/resources?text=research\%20supervision

Harrison, S. (2011). There's a fine line between pleasure and pain: Why students enrol in higher degrees in music and music education. Australian Journal of Music Education 2011(1), 66-75. Retrieved 30 September, 2013, from Informit database.

Harrison, S. D. (2013). Pro-active music higher degrees: Promoting, acting on and evaluating quality teaching and learning in music higher degrees. [Report]. Retrievable from http://www.olt.gov.au/resources/good-practice

Harrison, S.D. (in press). Training the singing researcher. In Harrison, S.D. \& O’Bryan, J. (Eds), Teaching Singing in the 21st Century. Dordrecht: Springer.

Harrison, S. D. \& Dwyer, R. (under review). Alleviating isolation: Research in the conservatoire. Manuscript submitted for review 1 June, 2013.

Heath, T. (2002). A quantitative analysis of PhD students' views of supervision. Higher Education Research and Development, 21(1), 41-53.

Hecq, D. (2009). Interactive narrative pedagogy as a heuristic for understanding supervision of practice-led research. New Writing: The International Journal for the Practice and Theory of Creative Writing, 6(1), 40-50. doi: 10.1080/14790720802598647

Hockey, J., \& Allen-Collinson, J. (2000). The supervision of practice-based research degrees in art and design. Journal of Art and Design, 19(3), 345-355. doi: 10.1111/1468-5949.00237

Johnson, L., A. Lee, and B. Green. 2000. The PhD and the autonomous self: Gender, rationality and postgraduate pedagogy. Studies in Higher Education 25(2), 136-147.

Lave, J. \& Wenger, E. (1991). Situated Learning: Legitimate Peripheral Participation. Cambridge, MA: Cambridge University Press.

Lee, A. (2008). How are doctoral students supervised? Concepts of doctoral research supervision. Studies in Higher Education 33(3), 267-81.

Lee, A. (2012). Successful research supervision: Advising students doing research. London: Routledge.

Mainhard, T., van der Rijst, R. \& van Tartwijk, J. (2009). A model for the supervisor-doctoral student relationship. Higher Education, 58(3), 359-373. doi: 10.1007/s10734-009-9199-8 
Manathunga, C., \& Goozée, J. (2007). Challenging the dual assumption of the 'always/already' autonomous student and effective supervisor. Teaching in Higher Education, 12(3), 309-322.

McCallin, A., \& Nayar, S. (2012). Postgraduate research supervision: A critical review of current practice. Teaching in Higher Education, 17(1), 63-74.

Murphy, N. (2009). Research supervision: Matches and mismatches. International Journal of Electrical Engineering Education, 46(3), 295-306.

Oxford Learning Institute (2012). Student-supervisor relationship. University of Oxford. Retrieved 30 April, 2012, from http://www.learning.ox.ac.uk/supervision/supervisor/relationships/

Paltridge, B., Starfield, S. Ravelli, L. J. \& Nicholson, S. (2012). Doctoral writing in the visual and performing arts: Two ends of a continuum. Studies in Higher Education, 37(8), 989-1003.

Pearson, M., and A. Brew. 2002. Research training and supervision development. Studies in Higher Education 27, 135-50.

Persson, R. (1994). Concert musicians as teachers: On good intentions falling short. European Journal for High Ability 5, 79-91.

Platow, M. J. (2012). PhD experience and subsequent outcomes: A look at self perceptions of acquired graduate attributes and supervisor support. Studies in Higher Education, 37(1), 103118.

Presland, C. (2005). Conservatoire student and instrumental professor: The student perspective on a complex relationship. British Journal of Music Education, 22(3), 237-248.

Samara, A. (2006). Group supervision in graduate education: A process of supervision skill development and text improvement. Higher Education Research \& Development 25(2), 115129.

Shacham, M. \& Od-Cohen, Y. (2009). Rethinking PhD learning incorporating communities of practice. Innovations in Education and Teaching International, 46(3), 279-292.

Sinclair, M. 2004. The pedagogy of 'good' PhD supervision: A national cross-disciplinary investigation of PhD supervision. Canberra: Australian Government, Department of Education, Science and Training.

Stock, C. (2009). Choreographing research: Supervising a dancing thesis. TEXT: The Journal of Writers and Writing Courses, 13(2). Retrieved 5 August, 2013, from http://www.textjournal.com.au/speciss/issue6/content.htm

'supervision' (2013, June). Oxford English Dictionary Online. Oxford University Press. Retrieved 5 August 2013, from OED database.

Taylor, S., \& Beasley, N. (2005). A handbook for doctoral supervisors. London: Routledge.

Wenger, E. (1998). Communities of Practice, Learning, Meaning and Identity. Cambridge, MA: Cambridge University Press.

Westerlund, H. \& Karlsen, S. (2013). Designing the rhythm for academic community life: Learning partnerships and collaboration in music educational doctoral studies. In Gaunt, H. \& Westerlund, H., Collaborative Learning in Higher Education, pp. 87-100. Surrey, UK: Ashgate.

Wisker, G. (2005). The good supervisor: Supervising postgraduate and undergraduate research for doctoral theses and dissertations. Basingstoke: Palgrave Macmillan.

Yeatman, A. (1995). Making supervision relationships accountable: Graduate student logs. Australian Universities' Review, 2, 9-11. 